\title{
A study on audience perception of minority design image
}

\author{
Jing Zeng \\ College of Forestry, Sichuan Agricultural University, Wenjiang 611130,China
}

\begin{abstract}
Keywords: Minority nationality; knowledge of origin; audience perception; social service Abstract. Minority elements of visual communication design is not only a form of national symbols, is a powerful way to expand the boundaries of ethnic culture cognition, for minority cultural heritage, ethnic elements of visual culture survival need to rely on the migration effect of art design to provide the original driving force, but also easy to design effect suffered the negative transfer of culture. This article focuses on the migration phenomenon of minority cultural design elements, analyzes the academic deviation of contemporary minority elements design sense to attract limitations, correct the concept of cultural transfer, cultural orientation and based on ontology and audience, explore the development and utilization of minority discourse system, which aims to provide a reasonable and effective design elements of national culture in the way, reveal the essence of social service of minority students knowledge structure.
\end{abstract}

\section{Audience perception in the design of minority elements}

Minority element design is based on visual art form based on visual design behavior through minority symbol modeling activities to convey specific information, because contains the history of minority nationalities along the specific image passed down the spirit connotation and no real, therefore need to exert psychological effects on the object passed through the national culture transfer. Cultural participation is particularly common in national design elements, from the perspective of aesthetic perception of cultural information visual recognition effect, for the cultural participation of audience interaction study little, including minority design elements of the national cultural resources mining limited in the sensory attract category, easy to cause the vagueness of the visual cultural transmission. For example, handmade paper packaging design of Hani Hani terraced fields into the wave elements, went up to the feasibility of the design that seems to be no ground for blame from Central Asia to the Middle East and, in the Near East, handmade paper packaging design in the world are used to distinguish the paper products and terrace elements of power machinery in different [1], but this is just the reflection of the the product concept, not to play the effect of national culture communication output, instead of handmade paper packaging Zhuang "terrace" design will be the one and only "symbol and terrace Longji Zhuang lines" combined with "the paper" gimmick to beat a world famous talent shows itself, the Hani terrace landscape craft paper, successful occupation market. "Terrace lines" and "terrace lines" although not a sensory experience, but have the function of aesthetic design, the difference is that the former national cultural output is fuzzy, the latter in the "Zhuang Yuechengling mountain" description also implies the Chinese dragon worship cultural charm, people have seen a stable psychological expectations for the national design elements, which requires elements not only to meet the patterns, lines, texture image, direct group appearance of pleasure, "should also be integrated, refraction non logic, used in image experience psychological [2], migration phenomenon in promoting cultural vision in the transfer process.

The design of the cultural elements of ethnic migration phenomenon occurs between the body and the receptor culture transfer through other elements will transplant specific national ideas, skills, aesthetic taste, etiquette and customs culture to design objects, promote mutual communication between different cultural audiences, and therefore not all cultural migration to be effective, the minority element in the design of cultural transfer phenomenon is a "positive transfer" and "negative transfer" points. Domestic academic research in the field of cultural transfer judgment is not clear, usually with "inadequate" cultural relevance of a short word, actually the most common ethnic elements of the design problem of our country is not lack of cultural relevance, but the existence of the relationship between the cultural information conversion fault "[3], such as modern interior 
decoration preferences using national elements to make decorative patterns, such as the design and application of Naxi Dongba hieroglyphs, Dai pattern and other national elements of the umbrella is not much, but the specific use in what place, how to use, how to use effects is another matter, such as lamp design, the Naxi dress cuff pattern to do circular decorative lampshade opening." neon "ignited" neon "conveys the aesthetic culture of Naxi pictograph is far more than to follow the trend of the current character design field. Therefore, ethnic elements design does not exist shortage of cultural relevance, but should transfer the study of convergence of cultural information is appropriate, for some designs, the destructive effect caused by improper cultural relevance can make the product image suffer a big. In modern commercial logo design on the application of parody of ethnic symbol as an example, the correlation China Unicom Company in order to highlight the communication with the heart, the commodity mark specially designed to modify Chinese Tibetan Buddhist culture in the other, using a total of three groups of Tibetan "Buddha mind" icon will be spliced into each other and the tail echo "Folian heart" image "," Buddha "and" family "homophonic, meaning through the heart of the service, for the sake of users" [4], this is a positive transfer of culture on behalf of the minority ethnic elements in design. The same is the Tibetan Buddhist culture pattern of uptake, a domestic tobacco companies of Tibetan Buddhist culture symbol and quiet, soft Wan open "roll grass pattern" used in cigarette packaging design is the cultural negative transfer performance of Tibetan Buddhist culture "grass" is the "treasure", "Vol. the grass" and "tobacco" rigid contact, is to "protect all the treasures of $\mathrm{Pu}$ " to indicate loss of tobacco to the body, not only lose the fear of conflict will, its semantic expression caused by two-phase conflict chaos experience. Therefore, the cultural transfer in the design of minority elements is bound to occur in a harmonious state of media interaction, so as to produce a truthful communication guide effectiveness.

\section{Audience perception in the design of minority elements}

Ethnic elements design as much as possible to avoid triggering culture positive transfer, negative transfer of culture, culture is the basic way of positioning, but so far, the research orientation of culture of ethnic minorities in China has not been able to design elements and cultural orientation of the mainstream design elements to differentiate the phase relationship between Guan Wenxian, grasp the people, culture and design three the usually standard for regional culture, there exist obvious differences between the essence of regional culture and national culture, the reason of this phenomenon is that contemporary minority elements appear in the design of multi commodity behavior, regional culture is closely related to the regional consumption, ambiguity design behavior used area symbols instead of national symbols easily lead to body culture the positioning and audience orientation of culture, caused the phenomenon of negative transfer of culture. For example, Miao clothing collar "well" pattern is to simulate the ecological layout of Miao area, if the "well" word lines appear in the collar of the Yao nationality clothing, is thought to have been entrusted with the Yao Water Worship folk culture connotation, when the "well" word lines appear in the collar of Tibetan costumes, will point to the Tibetan culture robe visible, geographical and cultural position of minority nationalities in the design elements will transfer with the change of audience identity, causing different cultural understanding and design of the main culture, the national culture positioning mode can effectively avoid the occurrence of the problem, such as the costumes of the Miao batik patterns and needle embroidery elements represent the technological level of special Miao and even if applied to other regions will not lose the function of cultural transmission exclusive.

The design of the cultural elements of ethnic minorities in order to establish orientation of cultural subject and cultural audience contact, so the extraction process of minority elements have a cultural perception of the design of the main aspects of the culture, so the degree of perception to consider it, and how to consider? The current research field that more cultural perception is the passive audience, the design of the main culture has covered audience square perception expectation, the author believes that even so, "the human cognition of the world is still in the organic boundary expanding in [1], ethnic elements have stable historical continuity, to promote the national elements of life in addition to the element itself cultural life, renewal and development, but also depends on the 
knowledge of discourse to the national elements, and constantly promote the cognitive boundary culture audience square development, so the minority element design of cultural transfer should have the characteristics of the times, reflecting the integration of interdisciplinary, and multiple grafting on the plane space the semantic expression, prompting people to contact with an understanding of contemporary art opened by ethnic elements" old window "[5 ]. For example, in the heyday of ethnic minorities in the southwest of China Ceramic economic development, rising trend is catching up with the design of the doctrine of $90 \mathrm{~s}$, the commodity label design of miniature pottery elements were all removed, replaced by the ceramic unfinished state of "mud", "glaze to body" and "spark" lines, artificial power of outstanding porcelain process, the transformation from "porcelain Qiao" to "15" perspective, the generation of life care for art practitioners, the creators of the unknown, the response and meet the new concept of art under the background of new era.

In addition, the minority elements in the design of culture positive transfer is also related to art performance strength, specific point of how to improve the national elements of the application of emotional appeal and spiritual appeal, emotional appeal of artistic expression to accommodate cognitive excitement, the spirit of appeal is to reach between the cultural subject and cultural value of the audience fit, prompting the latter to obtain social identity from the design. For example, to form Bai women's jewelry design materials, "clothes hanging ears with tassels symbol of Shimonoseki wind, white snow, Cangshan hat symbol to the symbol of Erhai crescent Earring [6] month" and so on, as the Yunnan cultural landscape "debauch" meaning, its romantic feelings, beautiful appearance of the national hint smoothly open the valve excited female aesthetic, "Naxi" seven "Cape element design by metaphor the Naxi Women break, hard work will character and moral sentiments" , effective convergence of national values, promoting the written by the experience of social identity number. Therefore, the minority element of design culture is not only the expression of the migration fit design thinking, but also reflects the people subject to the outstanding artistic character in minority element selectivity, the design of the cultural transfer phenomenon implies the cultural competition elements, cultural information identifiability, rationalization, form the visual aesthetic feeling of good to hear or see the conception of the lofty style, works will culture the result of selection about the audience. The western modern design theory, design elements of minority culture in the migration of the source in the culture, beyond culture, because of human practice of artistic expression constantly challenge themselves and invent new forms, release the imagination, it is because of development of art design characterization of ethnic elements, which makes the traditional culture of preaching, rigid, experimental with the harmony of components decreases, the survival ability of "serious form and from the category of politics, history, nature and the new awakening with fresh vitality", "as the design object".

\section{Audience perceived value in the design of minority elements}

A few design elements and cultural transfer ethnic minority areas of the cultural industry is closely related to the development, people generally think benefit cultural participation from the economic level, but the visual communication, minority culture transfer ethnic elements in the design of the most direct effect is to the popular way to subtly guide the mass culture grade of ". There have been significant differences in the research of the relevant literature, that is, what is more important to the social influence of the design of minority elements and the design of mainstream elements? One view is that the difference value of minority elements and public value system for large public events of the people gathered more benefit from the use of mainstream design elements of cultural introspection, but from the perspective of cultural transfer, the biggest feature of minority elements is the emphasis on national culture, and "any kind of excellent the national culture can enrich the individual of ego cognition", national cultural identity in the sense of substitution helps people see the relationship between culture and ego. For example, city life on the pursuit of "elegance", a benchmark of elements by the mainstream design elements usually covered city Gold Coast line, rustling palm tree, afternoon cafe and so on to highlight the quality of life, but if you consider the application of ethnic minority elements are wonderful chemical reaction, the ethnic minorities in Yunnan city propaganda as an 
example elegant taste, in the life of "elegance" to Yunnan Pu'er adult drawing blue and white porcelain "elegance", and based on the Yunnan minority culture in the "good" to express the people's life in the pursuit of perfection, the so-called "nature outside, in the heart of, a few are the spirit and soul of the national culture of dependency that can often get the public to start from the inside affirmation of life.

The design industry is not cultural types of high and low points, Andre Gide said: "the important thing is not to see your eyes, but that they are on the national voice sound designers", the design of the cultural elements of ethnic minority migration essence is a national discourse system spread, and the result of cultural transfer is to further promote the social public share of history, and to share and exchange the culture against the background based on common growth, progress, sublimation, in a sense, the minority cultural design elements promote the rational development of the migration of visual communication design, the more heterogeneous design atmosphere more rational and inclusive can absorb the minority element, the public culture the advocate is more powerful, the reason is not the national culture in the aspects of virtue advocate social advantage, but because of ethnic elements The origin of knowledge structure itself has the basic function of social service. Western knowledge management will be divided into two parts of human knowledge base system and value system, due to changes in knowledge system in mainstream society is more severe, basic system (material culture) and value system (often spiritual culture) are not in the same level, the stability of knowledge exist on the same level which is called "students the source of knowledge, the more knowledge of the nation, the social structure is more stable, more profound national cultural heritage, cultural transfer is more smooth, if the cultural transfer of minority element in the design is not smooth or the occurrence of the phenomenon of negative transfer of culture, we can often find the design style and there must be a national source of knowledge conflict or out of place. Such as the Han people in the tea culture in the promotion of Tibetan tea drinks usually rejected, the reason lies in the cognitive system of Tibetan tea culture in the concept of "tea beverage", Tibetan tea is to eat, the nutrition knowledge classification also with the Han nationality society there exist obvious difference.

Therefore, students of knowledge structure is the minority element design can not ignore the field of "logic", they permeate in national life in all aspects of basic necessities of life, ethnic elements design cultural transfer based on such students knowledge mining, transformation and utilization. In the process of cultural transfer in minority students knowledge in accordance with the designer's knowledge to create value, the social service function for the information services, cultural transfer is the transfer of knowledge and information, "the designer to design the object knowledge capture, analysis, restructuring, application process created the dynamic process of national culture continuous service, the value system of students knowledge represented not only can maintain between individual minority and ethnic community relations, but also as a starting point, the formation of inheriting the excellent national culture and develop communication style, rural and wilderness minority is" scattered ", but the mainstream city is community harmony" set ", so far, how to design different ethnic elements to maintain social relationships is still a controversial issue, but The infinite possibility of art lies in this, and the additional gain created by the design of minority elements is that through the experience of the excellent national culture, people can be respectful in the face of all things.

\section{References}

[1]LlU Yu-xian, YIN Zhi-ming.on Ethnic Elements Use in Modern Art \& Design[J].Journal of Kunming Metallurgy College,Sep. 2012

[2] You Jin Tan.The nationalization of graphic design[D].Central University For Nationalities,2013

[3]Xin $\mathrm{Ju}$ ou.On the cultural connotation and expression of aesthetic connotation of national design[J].Journal of Minzu University of China,2012, (9) 
[4]Jiangzaixin.The application of Mongolia traditional cultural elements in packaging design[J].Guizhou Ethnic Studies,2013, (6)

[5]Liu Zhen.A study on the type system of design art criticism[J].Art Design Research,2014, (2)

[6]Zhangluning.Research on audience perception in design[D].nanjing arts institute,2012 